\title{
The Experience Factor: A Regional Airline View of Pilot Candidate Qualifications
}

\author{
Richard O. Fanjoy, John P. Young, and Michael W. Suckow \\ Purdue University
}

\section{INTRODUCTION}

Airline hiring practices have been cyclical in nature over the last several decades, generally following economic trends. When the national economy is healthy, hiring occurs at all levels general aviation, corporate aviation, regional airlines, and major airlines (BTS, 2006). During these times, highly experienced flight crewmembers are sought by all sectors of the industry. While there are some common hiring criteria, e.g. flight time and FAA certification, each company determines its own composite hiring scheme. The purpose of this paper is to highlight experience considerations above and beyond flight time and certification level, which are viewed as critical attributes for prospective airline pilots. While operators want to hire the most experienced aviators, high flight time and number of FAA ratings are only part of the equation. What weight is accorded various experience factors by industry employers? What is the basis for these determinations? A survey of prospective airline employers may provide insight to these questions and be especially helpful for flight training program administrators who wish to find employment for their relatively low flight time graduates.
\end{abstract}

ABSTRACT

Pilot hiring by the regional airlines has finally begun to rebound from the downturn that followed the events of September 11, 2001. While major airlines have traditionally hired aviators with high-time military flight experience, greater numbers are now being selected from the general aviation population. Regional airlines, in particular, depend on recruitment of less experienced aviators to sustain their rapidly expanding sector of commercial aviation. This study sought to determine the experience factors that regional airline managers consider important to the selection process for new hire pilots. Key administrators at eleven regional airlines were surveyed to identify their current hiring criteria and perceptions of applicant quality. Findings from this study provide useful insights for flight training program development as well as individual applicant preparation.

\section{LITERATURE REVIEW}

A significant body of research has been completed to predict the success of military aviators (Hunter \& Burke, 1994; Martinussen, 1996; Ree \& Carretta, 1996; Turnbull, 1992). In the early years of military aviation, cognitive ability testing was considered the primary selection factor. The requirements of combat flying in World War II led to additional predictive assessments of pilot candidates to include intelligence, psychomotor, spatial, and mechanical testing (Flanagan, 1946; Griffin \& Koonce, 1996; Klein, 1948). Since that time, there has been continuing interest in predictive measurements of prospective flight crewmembers. More recent testing batteries have included psychological and behavioral measurement, personality assessment, and stress tolerance evaluation (Ree \& Carretta, 1996; Turnbull, 1992). The airlines have traditionally recruited former military pilots, and current hiring practices in commercial aviation have certainly been influenced by predictive measurements that were developed for the military.

Hunter and Burke (1994) conducted a metaanalysis of aircraft pilot-selection measures from 68 military studies completed from 1940 to 1990. Their analysis suggested significant predictive power in measures such as quantitative ability, spatial ability, mechanical ability, aviation information, general information, gross dexterity, perceptual speed, reaction time, biographical inventory data, and job performance. However, they noted a decline in predictor validity within the studies since 1961 due to the smaller sample sizes associated with those studies. Martinussen (1996) analyzed 50 studies that examined pilot performance predictors. Her meta-analysis of the data included studies from 11 different countries, 
conducted from 1919 to 1993 . While consistent information was often difficult to obtain, Martinussen divided the predictors into nine categories: cognitive tests, intelligence tests, psychomotor/information processing tests, aviation information tests, personality tests, biographical inventories, combined index, academics, and training experience. Correlations derived during this study suggest that pilot selection batteries should focus on measurements of cognitive, psychomotor/information processing, and motivational factors to identify successful candidates. Martinussen also recommends that previous training experience should be included in any predictive formula; while less emphasis should be placed on general intelligence tests, academics, biographical inventories, and personality tests.

Researchers have identified a wide variety of additional predictive factors for success as an aviator. Jensen (1995) states that good judgment is critical to pilot success, especially when developed through meaningful experiences rather than accrued flight time. Although he views good judgment as a subjective quality, valid tools have been developed to measure this trait, even before training occurs. Crew resource management (CRM) skills have also been included as a necessary quality for working in a team environment (Hedge, Bruskiewicz, Borman, Hanson, \& Logan, 2000; Helmreich, Wiener, \& Kanki, 1993). New strategies have been developed to validate predictors of effective crew performance, allowing for discrimination among individuals. These measurements take into account motivation and interpersonal skills that enhance group processes. As less experienced pilots are hired into today's transport aircraft, Hedge, et al. (2000) predict future selection boards will rely more on aptitude tests, especially in the area of effective crew coordination. Frey, Thomas, Walton, and Wheeler (2001) assert that situational awareness, or a person's mental model of the surrounding world, is essential to safe and expert pilot performance. Their research focused on a commercially available test to measure situational awareness and stress. While they found some validity in measurements of situational awareness during a simulated flight, they identified a need for better alignment of selection, training, and performance measures.

Damos (1996) has been studying pilot selection systems for several years. The results of her investigations suggest that a majority of pilot selection tests predict training performance rather than operational performance. The complexity and magnitude of pilot tasks (from preflight to postflight) make operational performance difficult to identify and measure, whereas performance during training is measured continuously, throughout the training program. In her more recent studies, Damos (2003) found that structured pilot selection systems are more effective than casual pilot selection systems for the identification of successful pilots. Casual selection systems typically rely on an individual judgment of an applicant's potential, often based on an informal interview and review of the applicant's paperwork. Reference to a company's hiring standards and mission may not occur during such an unstructured approach. Structured pilot selection systems, on the other hand, include consistent written and/or computer-based evaluations of candidate knowledge, skills, and abilities that are required to assess pilot competency and forecast success. These evaluations may also address personality, information processing, intelligence, and airplane/simulator performance. Damos (2003) has proposed strategies for designing effective pilot selection systems with improved predictive validity to support company requirements.

Flight experience levels of major airline new hires have increased over the last few years, yet these levels have actually decreased for their regional airline counterparts (Tippens, 2005). Most major airlines require a minimum of 1,500 hours of pilot-in-command turbine time for employment consideration, but candidates typically have several times that amount. Many regional air carriers, on the other hand, have lowered their minimum flight experience requirements to well below 1,000 hours. Some universities and colleges have developed bridge programs with regional airlines. In these programs, coursework and flight training is tailored to the partner airline's procedures and graduates become eligible for employment with 
only a few hundred hours (Karp, 2004). Tippens (2005) asserts that regional airline employers, to accurately assess the reduced experience levels of currently available pilot candidates, have significantly modified elements of their hiring process to provide heightened scrutiny and increased predictive validity. The current study was designed to identify experience factors considered important by regional airline employers and to determine how employers view this younger, less experienced candidate pool.

\section{METHODOLOGY}

A phone survey was developed to assess regional airline attitudes regarding experience levels of new pilot candidates. The survey was used to collect information on the pilot hiring process, types of evaluation instruments used, relative value assigned to attributes and traits, changes in the employer's evaluation method over time, and biographical data associated with the person interviewed. The survey was administered to a sample of regional airline upper level managers. The targeted population included all U.S. regional airlines that provide scheduled domestic passenger and cargo service with an aircraft fleet that is principally limited to fewer than 70 seats. Nineteen airlines in this category were identified, along with contact information of either the Chief Pilot or Director of Operations, from the current edition of the World Aviation Directory (2005). Respondents were advised of the purpose of the study, received assurances of confidentiality, and were then given the survey questions. The authors were able to obtain survey information from company officials at 11 of 19 airlines for a $58 \%$ response rate.

\section{FINDINGS}

Although the operational experience of survey respondents may add some level of bias to the data, the authors believe the responses provide a reasonable representation of current regional airline hiring practices. An analysis of the biographical data collected from the respondents suggests many commonalities among regional airline equipment, employment practices, and management structures. Equipment operated by the eleven respondents totaled 925 aircraft with the majority being regional jet variants. Some operators also use older Embraer 120, Saab 340, and DHC-8 aircraft. The average number of aircraft operated by regional airlines in the survey population was 84 and the range varied widely from 20 to 200 aircraft per airline. To support this inventory, most responders reported a current hiring rate of 100 - 200 new pilots per year.

The first few questions on the survey addressed minimum experience requirements stipulated by employers. Detailed information about these requirements can also be found on most company websites, website chat rooms, and other aviation media sources. Six of the eleven respondents stated a minimum flight time requirement of 1,000 hours and the remainder set 1,500 hours as the minimum. The multiengine experience requirement for most respondents ranged from 100 to 500 hours, with two respondents indicating that they did not have a multi-engine minimum. All of the respondents required a commercial certificate with an instrument rating and two required successful completion of the Air Transport Pilot written examination for employment. Although most employers prefer applicants with a four year college degree, that level of education was not required. When asked what additional value they place on graduate education, most said "none". Three respondents, however, felt graduate work demonstrated an important commitment towards improving a candidate's career potential. Finally, respondents were asked about the percentage of hiring decisions based on factors beyond the minimum requirements and their responses varied from 20 to 85 percent. It is unclear whether these responses reflect higher values in the established minimum categories, such as flight time, or whether the respondents were reporting consideration of additional categories such as personal attitudes or CRM.

Most airline employers have a structured candidate evaluation process that includes a variety of instruments to assess skill levels and compatibility with company operating style. When asked what types of tests they used during the pilot selection process, eight respondents identified airman knowledge tests with questions 
drawn from the ATP written test guide book and six included a flight simulator evaluation. When asked what consideration testing received in the hiring process, most respondents indicated a relatively strong influence (4 on a 5-point Likert scale). Interestingly, almost half of the respondents did not have strong confidence in the ability of current test instruments to predict successful candidates, even though testing received higher weight than most other predictors. When asked why they did not make better use of predictive instruments, responses included: do not trust, do not need, and poor cost/benefit tradeoff. Two respondents noted that the CRM aspect of their simulator evaluations provided sufficient insight that would otherwise be obtained with psychological profile testing.

Respondents were asked what additional skills, traits, and attributes were important to applicant consideration. Responses to this question did not suggest a common theme, but rather a broad spectrum of considerations that may reflect individual company values and direction. Identified attributes included: first impression of attitude, type of flying environment experience, past equipment flown, communication skills, career goals, and potential for success. Following this question, respondents were asked to rank the importance of a wide variety of candidate traits on a Likert scale from 1 (low) to 5 (high). Average values were calculated from survey responses. High importance was associated with candidates who were team players (4.7), trainable (4.6), had good CRM skills (4.5), and current flight experience (4.2) (see Figure 1). Low importance was associated with completion of an A\&P certificate program (2.8), military experience (2.5), and age of candidate (1.8) (see Figure 2). Respondents found other assessed traits to have moderate importance, including: college education (3.9), prior Part 121/135 experience (3.9), turbine engine experience (3.7), total time (3.2), glass cockpit experience (3.2), and advanced simulator experience (3.1) (see Figure 3).

Supply and demand for the current pilot pool was the last area addressed on the survey. With a continuing decline in the availability of military pilots, employers must look to a civilian

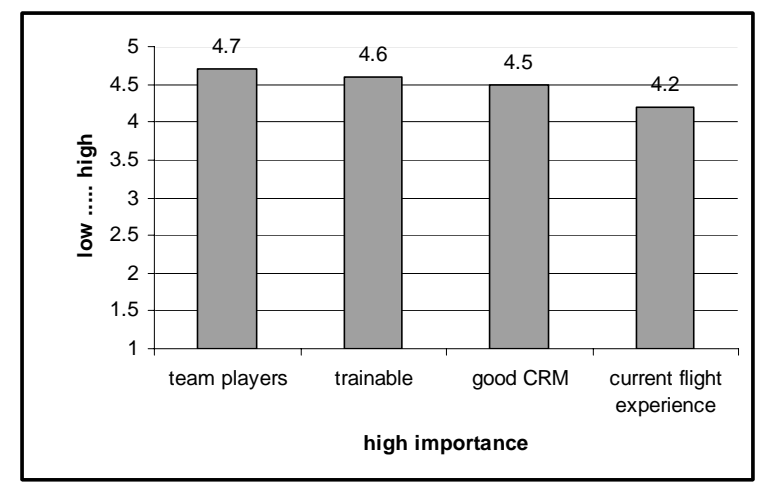

Figure 1. High importance of candidate traits

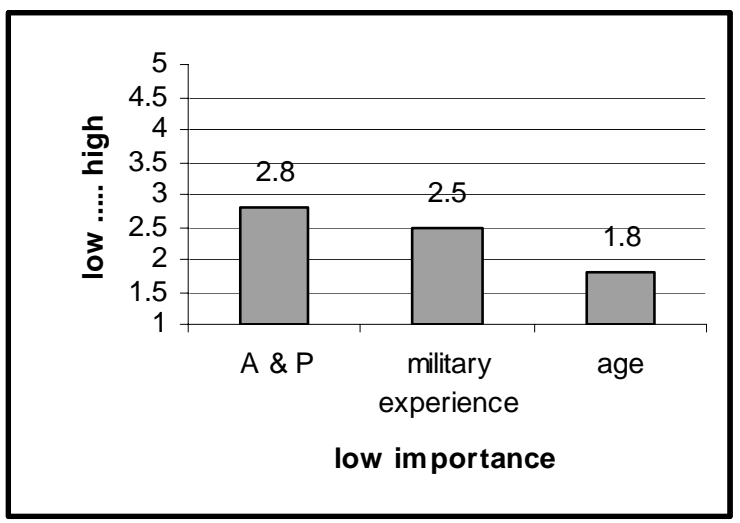

Figure 2. Low importance of candidate traits

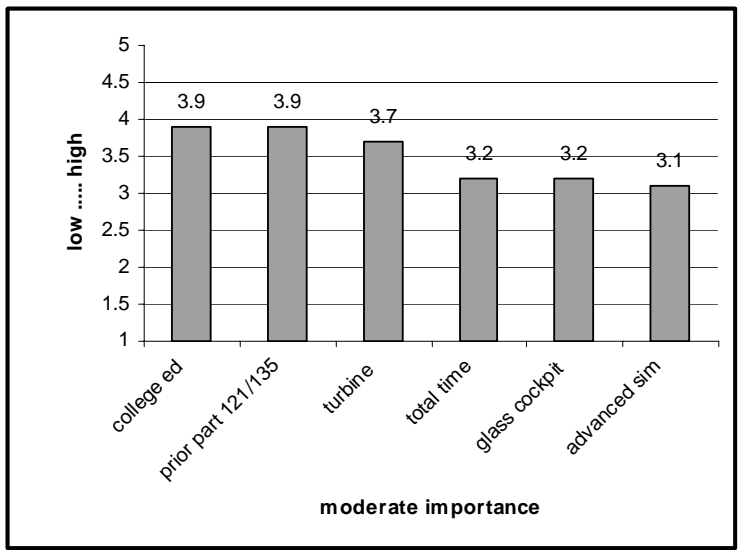

Figure 3. Moderate importance of candidate traits

pilot pool with much less flight experience. Half the respondents said that they lower their minimum flight experience requirements in response to the demand and availability of more experienced pilot candidates. During a pilot shortfall, employers have to fill pilot seats to maintain company profitability, and may need to work with a larger pool of lesser experienced 
pilots. The remaining survey respondents said they do not change minimums, but merely cast a wider net and expand the number of "looks" at each candidate. All respondents said that when experience levels drop in the available pilot pool, they expect training failure rates to go up and higher numbers of new hires to not complete probation. On the other hand, when fewer pilots are needed due to market pressures or company downsizing, employers have the luxury of raising the experience bar to take advantage of the most highly qualified candidates. This situation benefits the regional employers who then acquire more experienced pilots with attributes they desire, including professional competency and an attitude that fits the corporate culture. When asked to rate the quality of the 2006 pilot pool, respondents reported an average of 3.5 on a 5 point scale of low to high. Respondents said they will closely examine this group to identify the candidates most likely to be successful. Their primary determinants of this potential, in no particular order, are good attitude, confidence, good knowledge levels, teamwork, interest in their particular airline, an ability to advance on time, and personal values similar to those of the company.

\section{CONCLUSION}

It appears that regional airline hiring has rebounded from post 9/11 levels, which left many new pilots scrambling for employment opportunities (BTS, 2006). With the increasing demand for additional pilots, however, comes a great concern from employers that seats may be filled by lesser experienced pilots. For regional airline employers in particular, the dilemma is to reduce inventory and cockpit seats or hire relatively inexperienced crewmembers based on some evaluation formula with questionable predictive validity. A rich body of literature details past research into various predictors of pilot success. Particular support has been indicated for judgment, situational awareness, and CRM as effective predictors of pilot success when evaluated in concert with flight time and aviation knowledge. The results of the current study suggest that regional airline employers highly value team players, trainable personalities, and a company-friendly attitude, along with flight experience. However, respondents to the current survey still depend on selection systems that focus on flight time as a determinant of technical competence and interviews that enable the interviewer to develop impressions regarding candidate attitude. Although structured evaluation models that employ a variety of evaluation instruments have been found to have great value in predicting pilot success, many survey respondents said they have little confidence in predictive measures that are based on qualitative attributes. In addition, findings from the current survey do not suggest support for age, military flight duty, or completion of additional technical training (such as an A\&P certificate) as predictors of success. More research is indicated to enhance predictive models for particular airline employers and the results of such work must reflect sufficiently high validity levels as to engender unreserved employer confidence.

The findings of this study also provide useful information for the aviation training community. Flight training operations, which have traditionally focused on stick and rudder skills and tests of entry-level knowledge, must broaden their curricula to include learning skills as well as practical instruction in interpersonal and decision-making skills. Such aspects of training must be present throughout the program and not limited to a capstone or charm school course that is presented towards the end of training. Renewed emphasis must also be placed on the use of advanced decision-making skills in a realistic operational context. Based on the findings of this study, regional airline employers select candidates that they believe will be easily trainable, able to professionally interact with other crewmembers and customers, and best reflect company values and principles. These employers expect pilot candidates who are able to do much more than just complete assigned flight tasks within numerical parameters. They expect polished professionals who are current in their flying experience and possess excellent crew resource management skills, allowing them to interact well with others in and out of the cockpit. And that means employers' expectation of experience is much more than FAA certificates and logged flight time. 


\section{REFERENCES}

Bureau of Transportation Statistics; US Department of Transportation (2006). Number of employees Certified carriers, 1970-2005). Retrieved July 19, 2006, from: http://www.bts.gov/oai.

Damos, D. L. (February, 2003). Pilot selection systems help predict performance. Flight Safety Digest. Flight Safety Foundation.

Damos, D. L. (1996). Pilot selection batteries: Shortcomings and perspectives. The International Journal of Aviation Psychology, 6(2), 199-209.

Flanagan, J. C. (1946). The experimental evaluation of a selection procedure. Educational \& Psychological Measurement, 6, 445-466.

Frey, B. F., Thomas, M. J., Walton, A. J., \& Wheeler, P. J. (2001). Wombat as an example of situational awareness testing in pilot selection: An argument for the alignment of selection, training, and performance. [CD] Proceedings of the Eleventh International Symposium of Aviation Psychology (pp.1-6). Columbus, OH: The Ohio State University.

Griffin, G. R., \& Koonce, J M. (1996). Review of psychomotor skills in pilot selection research of the U.S. military services. The International Journal of Aviation Psychology, 6(2), 125-147.

Hedge, J. W., Bruskiewicz, K. T., Borman, W. C., Hanson, M. A., \& Logan, K. K. (2000). Selecting pilots with crew resource management skills. The International Journal of Aviation Psychology, 10(4), 377-392.

Helmreich R. L., Wiener, E. L., \& Kanki, B. G. (1993). The future of crew resource management in the cockpit and elsewhere. In E.L. Wiener, B. G. Kanki, \& R. L. Helmreich (Eds.), Cockpit Resource Management (pp. 479-501). San Diego, CA: Academic Press, Inc.

Hunter, D. R., \& Burke, E. F. (1994). Predicting aircraft pilot-training success: A meta-analysis of published research. The International Journal of Aviation Psychology, 4(4), 297-313.

Jensen, R. S. (1995). Pilot judgment and crew resource management. Aldershot, England: Ashgate Publishing Limited.

Karp, M. R. (2004). Airline pilot training: A university to regional airlines bridge training model. International Journal of Applied Aviation Studies, 4(1), 185-204.

Klein, G. S. (1948). Self-appraisal of test performance as a vocational selection device. Educational and Psychological Measurement, 8, 69-84.

Martinussen, M. (1996). Psychological measures as predictors of pilot performance: A meta-analysis. The International Journal of Aviation Psychology, 6(1), 1-20.

Ree, M. J., \& Carretta, T. R. (1996). Central role of g in military pilot selection. The International Journal of Aviation Psychology, 6(2), 111-123.

Tippens (2005). All change on the western front. The Journal for Civil Aviation Training, 5, 10-14.

Turnbull, G. J. (1992). Review of military pilot selection. Aviation, Space, and Environmental Medicine, 63, 825-830.

World Aviation Directory \& Aerospace Database (2d ed.). (Winter, 2005). Washington D.C.: The McGraw-Hill Companies. 